\title{
Genetic basis of autism spectrum disorder
}

\begin{abstract}
Autism Spectrum Disorder (ASD) comprises a wide range of neuro-developmental disorders characterized by difficulties with social communication and interaction, as well as restricted and repetitive patterns of behavior, interests and activities. It has a number of symptoms including cognitive, behavioral, and sensory symptoms. In addition, sleeping and eating difficulties, synesthesia as well as dysregulation and difficulty with initiation, planning and organization of tasks, are present. The identification of chromosomal abnormalities and Mendelian syndromes among individuals with Autism, along with linkage data from genome screens and candidategene studies, has helped delineate the complicated genetics that underlies Autism Spectrum Disorder.
\end{abstract}

Keywords: genetic, autism spectrum disorder, genetic mutations, chromosomal microarrays

\author{
Volume 4 Issue 2 - 2017
}

\author{
Nadeem Kizilbash,' Tanveer Ahmad Khan, ${ }^{2}$ \\ Shumaila Samad Khan, ${ }^{3}$ Faiza Meer $^{4}$ \\ 'Department of Medical Laboratory Technology, Northern \\ Border University, Saudi Arabia \\ ${ }^{2}$ Faculty of Pharmacy,Al-Jouf University, Saudi Arabia \\ ${ }^{3}$ Department of Biotechnology, University of Karachi, Pakistan \\ ${ }^{4}$ Faculty of Allied Health Sciences, The University of Lahore, \\ Pakistan
}

Correspondence: Nadeem Kizilbash, Department of Medical Laboratory Technology, Northern Border University, Saudi Arabia,Email fsd707@gmail.com

Received: April 18, 2017| Published: May 04, 2017

\section{Literature survey}

The greatest progress in the discovery of genetic causes of Autism is from identification of genetic mutations and disorders that can predispose to Autism. Using standard evaluation techniques such as the use of chromosomal microarrays (CMAs), a genetic cause can be identified in $20-25 \%$ of children in the Autism spectrum. A small number of cases have been discovered by tracing exposure to specific teratogens. ${ }^{1}$ For the remaining $75-80 \%$ of the cases, the causes remain unknown. Medical Genetics clinics have found the highest percentage of disorders, whereas specialized Autism clinics have found the lowest. ${ }^{2,3}$ The Genetic Association Database ${ }^{4}$ provides online access to genetic data for Autism and other disorders. Many reviews of the current status of candidate genes and loci are available. $^{5-14}$ SFARIGENE is a new web-based search engine for candidate genes associated with ASD. ${ }^{14}$ Table 1 lists some of the known Autism-related genes organized by pathogenesis of the disease. Particularly interesting are the synaptic cell adhesion molecules such as Neurexin 1, Neuroligin 3 and 4, and SHANK3, which implicate Glutaminergic synapse abnormalities with ASD. Mutations in the X-linked Neuroligin-3 (NLGN3) and Neuroligin-4 (NLGN4X and NLGN4Y) genes ${ }^{6,15}$ have been linked to Autism..$^{16,17}$ Laumonnier et al. ${ }^{17}$ have identified a two base-pair deletion in NLGN4 in members of a French family exhibiting X-linked mental retardation. Jamain et al. ${ }^{16}$ identified a C-to-T transition in the NLGN3 gene in two siblings, one with autism and the other with Asperger Syndrome. People suffering from ASD and carrying mutations in NLGN4 and NLGN3 are typically non-dysmorphic. Genetic testing of NLGN4 and NLGN3 is important in families suspected of having X-linked Autism. ${ }^{17}$ The SHANK3 gene is crucial for the development of language and social cognition. SHANK3 mutations and small cytogenetic rearrangements have been implicated with ASD. ${ }^{18,19}$ In addition, SHANK3 mutations have been found in Attention Deficit Hyperactivity Disorder (ADHD) and language disorders; suggesting that they may cause disease by acting synergistically with other genes.

Table I Some of the known Autism-related genes

\begin{tabular}{ll}
\hline Protein name (Function) & Gene/Locus \\
\hline Neuronal cell adhesion and/or synapse function & \\
\hline Neuroligin 3 (synapse formation and function) & NLGN3X Xq28 \\
Neuroligin 4 (synapse formation and function) & NLGN4X Xp2323 \\
Neurexin I (transsynaptic binding partner for Neuroligin) & NRNXNI 2pI63 \\
SH3 and multiple ankyrin repeat domains (organizes post synaptic density and binds Neuroligin) & SHANK3 22ql3 \\
$\begin{array}{l}\text { Contactin-associated protein-like 2 (synaptic binding partner for contactin molecules involved in } \\
\text { neuronal migration) }\end{array}$ & CNTNAP2 7q36 \\
Contactin 4 and Contactin 3 (neuronal expressed adhesion molecules) & CNTN4 and CNTN3 6p26-p25 \\
Protocadherin I0 (cadherin-related neuronal receptor) & PCDHI0 4q28 \\
Neuronal cell adhesion molecule & NRCAM 7q3I \\
\hline Neuronal activity regulation & \\
\hline Methyl CpG-binding protein I (CAN methylation-dependent transcriptional repressor) & MECP2 Xq28 \\
Ubiquitin protein ligase E3A & UBE3A I5qII-qI3 \\
\hline
\end{tabular}


Table Continued...

\begin{tabular}{|c|c|}
\hline Protein name (Function) & Gene/Locus \\
\hline Deleted in Autism & DIAI (c3orf58) 3q \\
\hline Ataxin 2-binding protein I & A2BPI 16pI3 \\
\hline \multicolumn{2}{|l|}{ Neurodevelopmental genes } \\
\hline Engrailed 2 (homeobox gene involved in midbrain and cerebellum development) & EN2 7q36 \\
\hline Homeobox AI (involved in hindbrain development) & HOXAI I7pI5.3 \\
\hline Homeobox BI (involved in hindbrain development) & HOXBI I7q21-22 \\
\hline Reelin (signaling protein involved in neuron migration) & RELN 7q22 \\
\hline WENT2 (signaling protein involved in embryonic patterning, cell proliferation and cell determination) & WNT2 7q3I \\
\hline FOXP2 (transcription factor involved in embryogenesis and neural functioning) & FOXP2 7q31 \\
\hline ARX homeobox gene & $A R \times X p 22.13$ \\
\hline Patched domain containing I gene & PTCHDI Xp22.II \\
\hline \multicolumn{2}{|l|}{ Sodium channel } \\
\hline Sodium channel, voltage-gated, type VII & SCN7A 2q \\
\hline $\mathrm{Na}^{+} / \mathrm{H}^{+}$exchanger isoform 9 & SLC9A9 (NHE9) 3q24 \\
\hline \multicolumn{2}{|l|}{ Calcium channel } \\
\hline Calcium channel, voltage-dependent, type I, alpha IC subunit & CACNAIC I $2 p \mid 3.3$ \\
\hline Calcium channel, voltage-dependent, alpha IH subunit & CACNAIH I6pI3.3 \\
\hline Calcium channel, voltage-dependent, type I, alpha IF subunit & CACNAIF XpII.23 \\
\hline \multicolumn{2}{|l|}{ Neurotransmitter genes } \\
\hline GABA receptor Subunits & GABRB3, GABRA5, GABRG3 $15 q \mid 1.2-q 12$ \\
\hline Serotonin Receptor & SLC6A4 I7qII.I-qI2 \\
\hline
\end{tabular}

Chromosomal abnormalities at the 15q11-q13 locus are commonly found in people with Autism. A "chromosome 15 phenotype" has also been described in individuals with chromosome 15 duplications. ${ }^{20}$ Among other candidate genes are the FOXP2, RAY1/ST7, IMMP2L, and $R E L N$ genes at $7 \mathrm{q} 22-\mathrm{q} 33$ and the GABA A receptor subunit and $U B E 3 A$ genes on chromosome 15q11-q13 (Table 1). Mutations in the serotonin transporter gene (5-HTT) on 17q11-q12 are more frequent in individuals with Autism than in non-Autistic populations. In addition, animal models and linkage data from genome screens have implicated the oxytocin receptor at 3p25-p26. ${ }^{21}$

\section{Future direction}

Awareness of the symptoms and causes of Autism is relevant for a pediatrician. In light of the increasingly high prevalence of ASD, pediatricians are likely to come across cases of this disorder in their practices. However, the genetics of Autism is still far from understood since we are only beginning to understand what controls human behavior. Promising strategies need to be applied to identify common genetic risk variants. Systems biology approaches, including array-based expression profiling, can provide an insight into Autism Spectrum Disorder, in which both genetic and phenotypic heterogeneity is a dominant theme.

\section{Acknowledgements}

None.

\section{Conflict of interest}

The author declares no conflict of interest.

\section{References}

1. Miles JH. Autism spectrum disorders - a genetics review. Genet Med. 2011;13(4):278-294.

2. Schaefer GB, Mendelsohn NJ, Professional Practice and Guidelines Committee. Clinical genetics evaluation in identifying the etiology of autism spectrum disorders:2013 guideline revisions. Genet Med. 2013;15(5):399-407.

3. Miles JH, Takahashi TN, Bagby S, et al. Essential versus complex autism: definition of fundamental prognostic subtypes. Am J Med Genet A. 2005;135(2):171-180.

4. Becker KG, Barnes KC, Bright TJ, et al. The genetic association database. Nat Genet. 2004;36(5):431-432.

5. Freitag CM, Staal W, Klauck SM, et al. Genetics of autistic disorders: review and clinical implications. Eur Child Adolesc Psychiatry. 2010;19(3):169-178.

6. Buxbaum JD. Multiple rare variants in the etiology of autism spectrum disorders. Dialogues Clin Neurosci. 2009;11(1):35-43.

7. Sutcliffe JS. Insights into the pathogenesis of autism. Science. 2008;321(5886):208-209.

8. Morrow EM, Yoo SY, Flavell SW, et al. Identifying autism loci and genes by tracing recent shared ancestry. Science. 2008;321(5886):218-223. 
9. Autism Genome Project Consortium, Szatmari P, Paterson AD, et al. Mapping autism risk loci using genetic linkage and chromosomal rearrangements. Nat Genet. 2007;39(3):319-328.

10. Barbaro J, Dissanayake C. Autism spectrum disorders in infancy and toddlerhood: a review of the evidence on early signs, early identification tools, and early diagnosis. J Dev Behav Pediatr. 2009;30(5):447-459.

11. Gupta AR, State MW. Recent advances in the genetics of autism. Biol Psychiatry. 2007;61(4):429-437.

12. McKusick VA. Mendelian Inheritance in Man and its online version, OMIM. Am J Hum Genet. 2007;80(4):588-604.

13. Banerjee Basu S, Packer A. SFARI Gene: an evolving database for the autism research community. Dis Model Mech. 2010;3(3-4):133-135.

14. Südhof TC. Neuroligins and neurexins link synaptic function to cognitive disease. Nature. 2008;455(7215):903-911.

15. Wang K, Zhang H, Ma D, et al. Common genetic variants on 5p14. 1 associate with autism spectrum disorders. Nature. 2009;459(7246):528 533.
16. Jamain S, Quach H, Betancur C, et al. Mutations of the X-linked genes encoding Neuroligin NLGN3 and NLGN4 are associated with autism. Nat Genet. 2003;34(1):27-29.

17. Laumonnier F, Bonnet-Brilhault F, Gomot M, et al. X-linked mental retardation and autism are associated with a mutation in the NLGN4 gene, a member of the neuroligin family. Am J Hum Genet. 2004;74(3):552557.

18. Durand CM, Betancur C, Boeckers TM, et al. Mutations in the gene encoding the synaptic scaffolding protein SHANK3 are associated with autism spectrum disorders. Nat Genet. 2007;39(1):25-27.

19. Moessner R, Marshall CR, Sutcliffe JS, et al. Contribution of SHANK3 mutations to autism spectrum disorder. Am J Hum Genet. 2007;81(6):1289-1297.

20. Folstein SE, Rosen-Sheidley B. Genetics of austim: complex aetiology for a heterogeneous disorder. Nat Rev Genet. 2001;2(12):943-955.

21. Wu S, Jia M, Ruan Y, et al. Positive association of the oxytocin receptor gene (OXTR) with autism in the Chinese Han population. Biol Psychiatry. 2005;58(1):74-77. 